Article

\title{
Simultaneously Improved Thermal and Dielectric Performance of Epoxy Composites Containing $\mathrm{Ti}_{3} \mathrm{C}_{2} \mathrm{~T}_{\mathrm{x}}$ Platelet Fillers
}

\author{
Lin Chen ${ }^{1, *}$, Yu Cao ${ }^{1}$, Xuebo Guo ${ }^{1}$, Ping Song ${ }^{1}$, Kai Chen ${ }^{2} \mathbb{D}$, Diansen $\mathrm{Li}^{3}$ and Jun $\mathrm{Lin}^{4, *}$ \\ 1 MOE Key Laboratory of Power Station Energy Transfer Conversion and System, School of Energy Power \\ and Mechanical Engineering, North China Electric Power University, Beijing 102206, China; \\ 13264243432@163.com (Y.C.); 120192202712@ncepu.edu.cn (X.G.); 1182202225@ncepu.edu.cn (P.S.) \\ 2 MOE Key Laboratory of Enhanced Heat Transfer and Energy Conservation, School of Chemistry and \\ Chemical Engineering, South China University of Technology, Guangzhou 510640, China; \\ chenkaihb09@126.com \\ 3 MOE Key Laboratory of Bio-Inspired Smart Interfacial Science and Technology, School of Chemistry, \\ Beijing University of Aeronautics and Astronautics, Beijing 100191, China; lidiansen@buaa.edu.cn \\ 4 School of Renewable Energy, North China Electric Power University, Beijing 102206, China \\ * Correspondence: chenlin@ncepu.edu.cn (L.C.); jun.lin@ncepu.edu.cn (J.L.); Tel.: +86-10-6177-3372 (L.C.); \\ +86-10-6177-2185 (J.L.)
}

Received: 23 June 2020; Accepted: 17 July 2020; Published: 19 July 2020

check for updates

\begin{abstract}
Polymer composites with enhanced thermal and dielectric properties can be widely used in electric and energy related applications. In this work, epoxy composites have been prepared with $\mathrm{Ti}_{3} \mathrm{C}_{2} \mathrm{~T}_{\mathrm{x}}$, one of the most studied MXene materials that can be massively produced by direct etching using hydrofluoric acid. The addition of conductive two dimensional $\mathrm{Ti}_{3} \mathrm{C}_{2} \mathrm{~T}_{\mathrm{x}}$ platelet fillers leads to improved but anisotropic thermal conductivity of the composites. The through-plane thermal conductivity reaches $0.583 \mathrm{Wm}^{-1} \mathrm{~K}^{-1}$ and the in-plane thermal conductivity reaches $1.29 \mathrm{Wm}^{-1} \mathrm{~K}^{-1}$ when filler content is $40 \mathrm{wt} \%$ (21.3 vol\%), achieving enhancements of 2.92 times and 10.65 times respectively, as compared with epoxy matrix. The dielectric permittivity of epoxy composite is enhanced by a factor of $\sim 2.25$ with $40 \mathrm{wt} \%$ fillers, and the dielectric losses are within a small value of 0.02 . The results prove the effectiveness of $\mathrm{Ti}_{3} \mathrm{C}_{2} \mathrm{~T}_{\mathrm{x}}$ in simultaneously improving thermal and dielectric performance of epoxy composites, and it is deduced that further improvements may be obtained by using $\mathrm{Ti}_{3} \mathrm{C}_{2} \mathrm{~T}_{\mathrm{x}}$ nanoflake fillers.
\end{abstract}

Keywords: MXene; $\mathrm{Ti}_{3} \mathrm{C}_{2} \mathrm{~T}_{\mathrm{x}}$; polymer composites; thermal conductivity; dielectric properties

\section{Introduction}

Polymer composites with substantially improved thermal conductivity $(k)$ [1-3] and dielectric permittivity $(\varepsilon)$ [4] are in great need for many applications, such as thermal interface materials $[5,6]$, heat dissipation and thermal management [7-9], microelectronics, and energy storage related applications [4,10-12]. Appropriate fillers with inherent high performance are essential for preparing these desired functional polymer composites. These days, a new class of two dimensional (2D) materials named MXene, which is often fabricated by selectively etching element A from " $M_{n+1} A X_{n}$ " ( $\mathrm{M}$ is an early transition metal, $\mathrm{A}$ is an A-group (mostly groups 13 and 14) element, $\mathrm{X}$ is carbon and/or nitrogen, and $n=1,2$, or 3) [13], receives a considerable amount of research attention [14]. To date, more than $20 \mathrm{MXenes}$ have been synthesized [15] and the most studied one is $\mathrm{Ti}_{3} \mathrm{C}_{2} \mathrm{~T}_{\mathrm{x}}\left(\mathrm{T}_{\mathrm{x}}\right.$ stands for the surface terminations of functional groups) [16], which has prospective applications in capacitors [17,18], electromagnetic shielding and absorption [19,20], water purification [21], and antibacterial activity [22]. 
In fact, $\mathrm{Ti}_{3} \mathrm{C}_{2} \mathrm{~T}_{\mathrm{x}}$ is also expected to be an ideal filler for preparing polymer composites with enhanced thermal and dielectric properties. Firstly, $\mathrm{Ti}_{3} \mathrm{C}_{2} \mathrm{~T}_{\mathrm{x}}$ is a good electrical conductor $[13,14,23]$, which helps to improve composite thermal conductivity and dielectric permittivity. Secondly, the laminated structure of $\mathrm{Ti}_{3} \mathrm{C}_{2} \mathrm{~T}_{\mathrm{x}}$ means large aspect ratio, which may result in high thermal conductivity [24] and good dielectric permittivity [4] by percolation. Thirdly, the abundant functional groups on $\mathrm{Ti}_{3} \mathrm{C}_{2} \mathrm{~T}_{\mathrm{x}}$ surface indicate possible good compatibility with polar polymers when used as fillers, which would lead to enhanced composite properties. When thermal conductivity is improved simultaneously with dielectric permittivity, the better heat dissipation associated with higher thermal conductivity can result in a more stable dielectric performance. Thus, using $\mathrm{Ti}_{3} \mathrm{C}_{2} \mathrm{~T}_{\mathrm{x}}$ as fillers may achieve a synergistic effect between the improved thermal and dielectric performance of polymer composites, potentially highly beneficial to the dielectric materials, because they always face the problem of the temperature rise caused by dielectric loss, which may eventually lead to material breakdown if the heat is not effectively dissipated.

In order to verify the above expectations and evaluate the effect of $\mathrm{Ti}_{3} \mathrm{C}_{2} \mathrm{~T}_{\mathrm{x}}$ on thermal and dielectric performance, the widely used epoxy resin [25-27] was chosen as the matrix and $\mathrm{Ti}_{3} \mathrm{C}_{2} \mathrm{~T}_{\mathrm{x}}$ /epoxy composites were prepared. According to our previous study on $\mathrm{Ti}_{3} \mathrm{C}_{2} \mathrm{~T}_{\mathrm{x}} \mathrm{MXene}$ films [28], there are roughly three forms of $\mathrm{Ti}_{3} \mathrm{C}_{2} \mathrm{~T}_{\mathrm{x}}$, including $\mathrm{Ti}_{3} \mathrm{C}_{2} \mathrm{~T}_{\mathrm{x}}$ micro-platelets/particles resulted from hydrofluoric acid (HF) etching of $\mathrm{Ti}_{3} \mathrm{AlC}_{2}$ (herein, termed as $\mathrm{HF}-\mathrm{Ti}_{3} \mathrm{C}_{2} \mathrm{~T}_{\mathrm{x}}$ ) and its derivants of un-delaminated multi-layer $\mathrm{Ti}_{3} \mathrm{C}_{2} \mathrm{~T}_{\mathrm{x}}$ nanoflakes $\left(\mathrm{ML}-\mathrm{Ti}_{3} \mathrm{C}_{2} \mathrm{~T}_{\mathrm{x}}\right.$ ) and delaminated few-layer $\mathrm{Ti}_{3} \mathrm{C}_{2} \mathrm{~T}_{\mathrm{x}}$ nanosheets $\left(\mathrm{FL}^{-} \mathrm{Ti}_{3} \mathrm{C}_{2} \mathrm{~T}_{\mathrm{x}}\right.$ ), as shown in Supplementary Figure S1. In this work, the HF- $\mathrm{Ti}_{3} \mathrm{C}_{2} \mathrm{~T}_{\mathrm{x}}$ filler was used due to its high yield during the preparation process of $\mathrm{Ti}_{3} \mathrm{C}_{2} \mathrm{~T}_{\mathrm{x}}$. Moreover, the results of $\mathrm{HF}_{-} \mathrm{Ti}_{3} \mathrm{C}_{2} \mathrm{~T}_{\mathrm{x}}$ /epoxy composites could set a benchmark for further work on composites prepared with the other two nanosized $\mathrm{Ti}_{3} \mathrm{C}_{2} \mathrm{~T}_{\mathrm{x}}$ fillers. The thermal and dielectric performance of the $\mathrm{HF}-\mathrm{Ti}_{3} \mathrm{C}_{2} \mathrm{~T}_{\mathrm{x}} / \mathrm{epoxy}$ composites were analyzed and correlated with their structure and morphologies.

\section{Materials and Methods}

\subsection{Materials}

$\mathrm{Ti}_{3} \mathrm{AlC}_{2}$ powder ( $98 \%$ purity) was supplied by 11 Technology Co., Ltd., China. Hydrofluoric acid $(\mathrm{HF}, 40 \mathrm{wt} \%)$ and ethanol were produced by Beihua Fine Chemicals, China. Epoxy resin (E-51) was produced by Sanmu Chemical Co., Ltd., China. Curing agent (3-methyl-tetrahydrophthalic anhydride, MeTHPA) and cure accelerator (2,4,6-Tris(dimethylaminomethyl)phenol, DMP-30) were purchased from TCI (Shanghai) Development Co., Ltd., China. All materials were used as received.

\subsection{Preparation of $\mathrm{HF}-\mathrm{Ti}_{3} \mathrm{C}_{2} \mathrm{~T}_{x}$ and Epoxy Composites}

$\mathrm{HF}$ was used to selectively etch the $\mathrm{Al}$ in $\mathrm{Ti}_{3} \mathrm{AlC}_{2}$ to obtain $\mathrm{Ti}_{3} \mathrm{C}_{2} \mathrm{~T}_{\mathrm{x}}$ via the procedures described in literature $[15,28,29]$. Briefly, $2.5 \mathrm{~g} \mathrm{Ti}_{3} \mathrm{AlC}_{2}$ powders were slowly added to $60 \mathrm{~mL} \mathrm{HF}$ which was contained in a plastic beaker. The mixture was magnetically stirred at $480 \mathrm{rpm}$ and $40{ }^{\circ} \mathrm{C}$ for $24 \mathrm{~h}$. In this way, the $\mathrm{Al}$ was selectively etched, turning the $\mathrm{Ti}_{3} \mathrm{AlC}_{2}$ into $\mathrm{HF}-\mathrm{Ti}_{3} \mathrm{C}_{2} \mathrm{~T}_{\mathrm{x}}$. The mixture was diluted by deionized (DI) water and centrifuged at $3500 \mathrm{rpm}$ for $5 \mathrm{~min}$ to obtain the precipitate. Then, the procedures of washing precipitate and centrifugation to separate the precipitate were repeated until the $\mathrm{pH}$ value of supernatant was 7 . The aqueous dispersion of $H F-\mathrm{Ti}_{3} \mathrm{C}_{2} \mathrm{~T}_{\mathrm{x}}$ was vacuum filtered to obtain the filter cake, which was washed by ethanol and then dried at $60^{\circ} \mathrm{C}$ for $24 \mathrm{~h}$, and the yield is $\sim 70 \mathrm{wt} \%$. The dried filter cake was later milled and used as fillers in epoxy composites.

Epoxy resin and curing agent (MeTHPA) with mass ratio of 100:85 were mixed with certain amount of $\mathrm{HF}-\mathrm{Ti}_{3} \mathrm{C}_{2} \mathrm{~T}_{x}$ fillers (5 40 wt $\%$ ). The mixture was magnetically stirred for $2 \mathrm{~h}$, followed by ultrasonication for $10 \mathrm{~min}$ and degassing for $10 \mathrm{~min}$. Afterwards, a cure accelerator (DMP-30, mass ratio of epoxy and accelerator is 100:1) was added to above mixture, which was successively stirred, ultrasonicated and degassed for a total $30 \mathrm{~min}$ (10 $\mathrm{min}$ for each process). Then, the composite fluid was slowly poured into pre-heated molds, which were manually inclined to enhance the composite 
fluid to flow around to fill the mold. After that, the composite fluid was cured at $100{ }^{\circ} \mathrm{C}$ for $4 \mathrm{~h}$ and $150{ }^{\circ} \mathrm{C}$ for $10 \mathrm{~h}$. The resulting epoxy composites were circle plates (diameter of $25.4 \mathrm{~mm}$ ) and square plates $(40 \times 40 \mathrm{~mm})$ with thickness of $\sim 0.5 \mathrm{~mm}$.

\subsection{Characterization and Measurements}

Scanning electron microscope (SEM) images of fillers and composites were taken by Quattro-S (Thermo Fisher Scientific, USA). Small fragments were mechanically fractured from the as-prepared epoxy composite plates by using tweezers, and the resulting cross sections were used for SEM observation. X-ray diffractometer (XRD) analysis was performed on SmartLab SE (Rigaku, Japan) under $40 \mathrm{kV}$ and $30 \mathrm{~mA}$ with a scanning speed of $2^{\circ} / \mathrm{min}$ from $3^{\circ}$ to $70^{\circ}$. Static water contact angles of the composites were measured by a telescopic goniometer (OCA15 EC, Dataphysics, Germany) by the sessile drop method. Thermal gravimetric analysis (TGA) was carried out on a thermal analyzer STA 449F5 (NETZSCH, German) under argon (Ar) atmosphere at a heating rate of $10^{\circ} \mathrm{C} / \mathrm{min}$ from 40 to $800{ }^{\circ} \mathrm{C}$. Thermal diffusivity $(\alpha)$ was measured by a laser flash method using an LFA 467 (NETZSCH, German), which can measure both through-plane and in-plane thermal diffusivities via applying corresponding specified sample holders. Specific heat capacity $\left(c_{P}\right)$ was measured by differential scanning calorimetry method using STA 449F3 (NETZSCH, German) with a heating rate of $2{ }^{\circ} \mathrm{C} / \mathrm{min}$. Density $(\rho)$ was measured by the buoyancy method using MH-300A (Qunlong, China). Then the thermal conductivity $(k)$, was obtained by $k=\alpha \cdot \rho \cdot c_{p}$. Dielectric properties were measured by a precision impedance analyzer WK-6510B (Wayne Kerr, UK) within the frequency range of $10^{2}-10^{6} \mathrm{~Hz}$ at room temperature.

\section{Results}

Figure 1a shows the accordion-like HF- $\mathrm{Ti}_{3} \mathrm{C}_{2} \mathrm{~T}_{\mathrm{x}}$ resulted from $\mathrm{HF}$ etching of $\mathrm{Ti}_{3} \mathrm{AlC}_{2}$ and the lateral dimension of $\mathrm{HF}_{-} \mathrm{Ti}_{3} \mathrm{C}_{2} \mathrm{~T}_{\mathrm{x}}$ is around $5 \sim 10 \mu \mathrm{m}$. Similar morphologies were also observed in literature $[15,28,29]$, which is regarded as an indication of successful removal of $\mathrm{Al}$ layers in $\mathrm{Ti}_{3} \mathrm{AlC}_{2}$. The results of XRD tests on $\mathrm{Ti}_{3} \mathrm{AlC}_{2}$ and $\mathrm{HF}-\mathrm{Ti}_{3} \mathrm{C}_{2} \mathrm{~T}_{\mathrm{x}}$ powders are shown in Figure $1 \mathrm{~b}$. For HF-Ti $\mathrm{C}_{2} \mathrm{~T}_{\mathrm{X}}$ powders, the characteristic (104) peak at $\sim 39^{\circ}$ disappeared and the (002) peak at $\sim 9.8^{\circ}$ shifted to the lower angle, as compared with $\mathrm{Ti}_{3} \mathrm{AlC}_{2}$ powders. These results agree well with those reported in references $[15,28,29]$, which further confirms the effective etching of $\mathrm{Al}$.
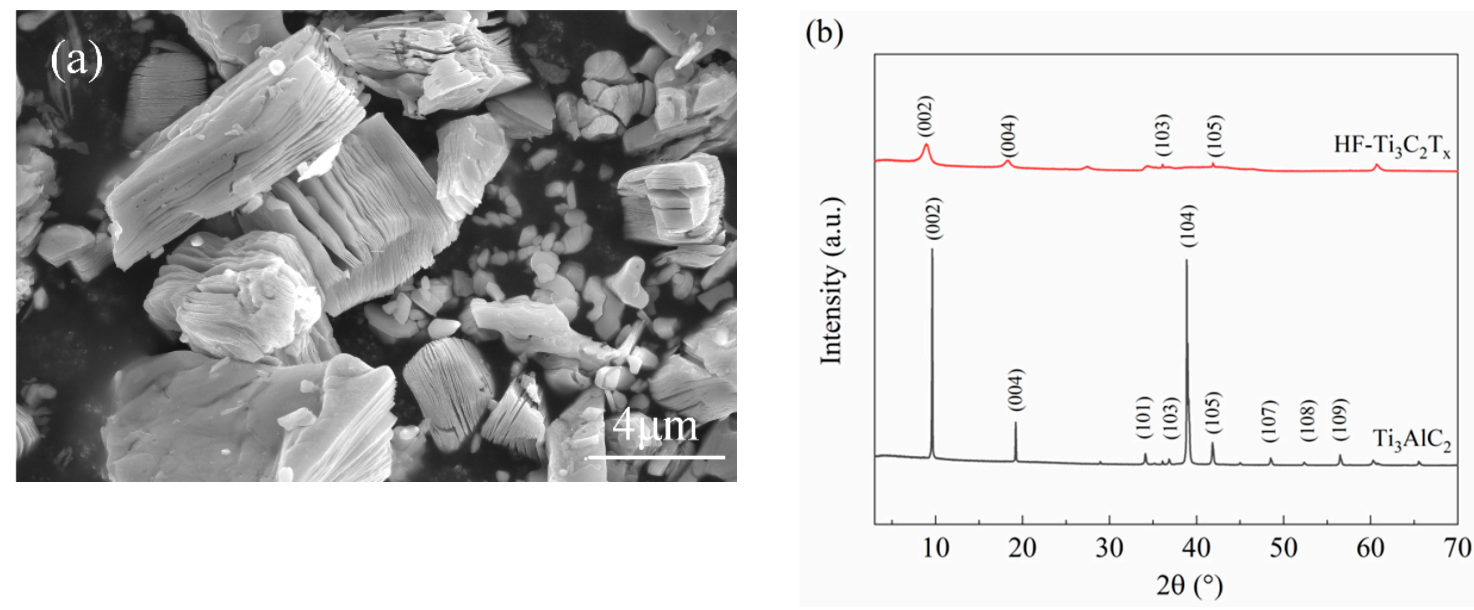

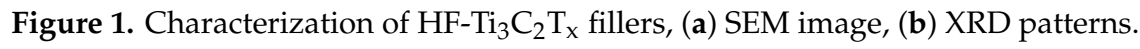

Figure 2a is an SEM image showing a smooth cross section of pure epoxy, in which the wavy patterns are resulted from mechanical fracture that is used to obtain the cross section of samples. Figure $2 \mathrm{~b}-\mathrm{f}$ are SEM images of cross sections of $\mathrm{HF}-\mathrm{Ti}_{3} \mathrm{C}_{2} \mathrm{~T}_{\mathrm{x}}$ /epoxy composites with different filler contents. In general, the HF- $\mathrm{Ti}_{3} \mathrm{C}_{2} \mathrm{~T}_{\mathrm{x}}$ fillers, which are stack shaped platelets with relatively transparent 
and light color in the SEM images, are dispersed quite well in epoxy. The interface of the filler and the matrix is compact, as indicated by the circle (Figure 2f) showing fillers fully embedded in the epoxy matrix. This good interfacial compatibility may reasonably be attributed to the abundant functional groups $\left(\mathrm{OH}, \mathrm{F}, \mathrm{O}, \mathrm{H}\right.$, etc.) on the $\mathrm{HF}-\mathrm{Ti}_{3} \mathrm{C}_{2} \mathrm{~T}_{\mathrm{x}}$ surface [14], which improve the interfacial adhesion through the possible formation of chemical bonding between filler and epoxy matrix. For the low filler content of $5 \mathrm{wt} \%$ or $10 \mathrm{wt} \%$, the platelet $\mathrm{HF}-\mathrm{Ti}_{3} \mathrm{C}_{2} \mathrm{~T}_{\mathrm{x}}$ fillers are mainly surrounded by epoxy matrix and isolated from each other, as shown in Figure $2 b, c$. When the filler content increases from $20 \mathrm{wt} \%$ to $40 \mathrm{wt} \%$, although the fillers still disperse homogenously in the matrix, the distance between fillers decreases and interconnections among fillers gradually appear, as shown in Figure $2 \mathrm{~d}-\mathrm{f}$. From Figure $2 b-f$, it is also found that the platelet fillers tend to distribute along the in-plane direction, as indicated by the dashed lines for filler and filler chains.
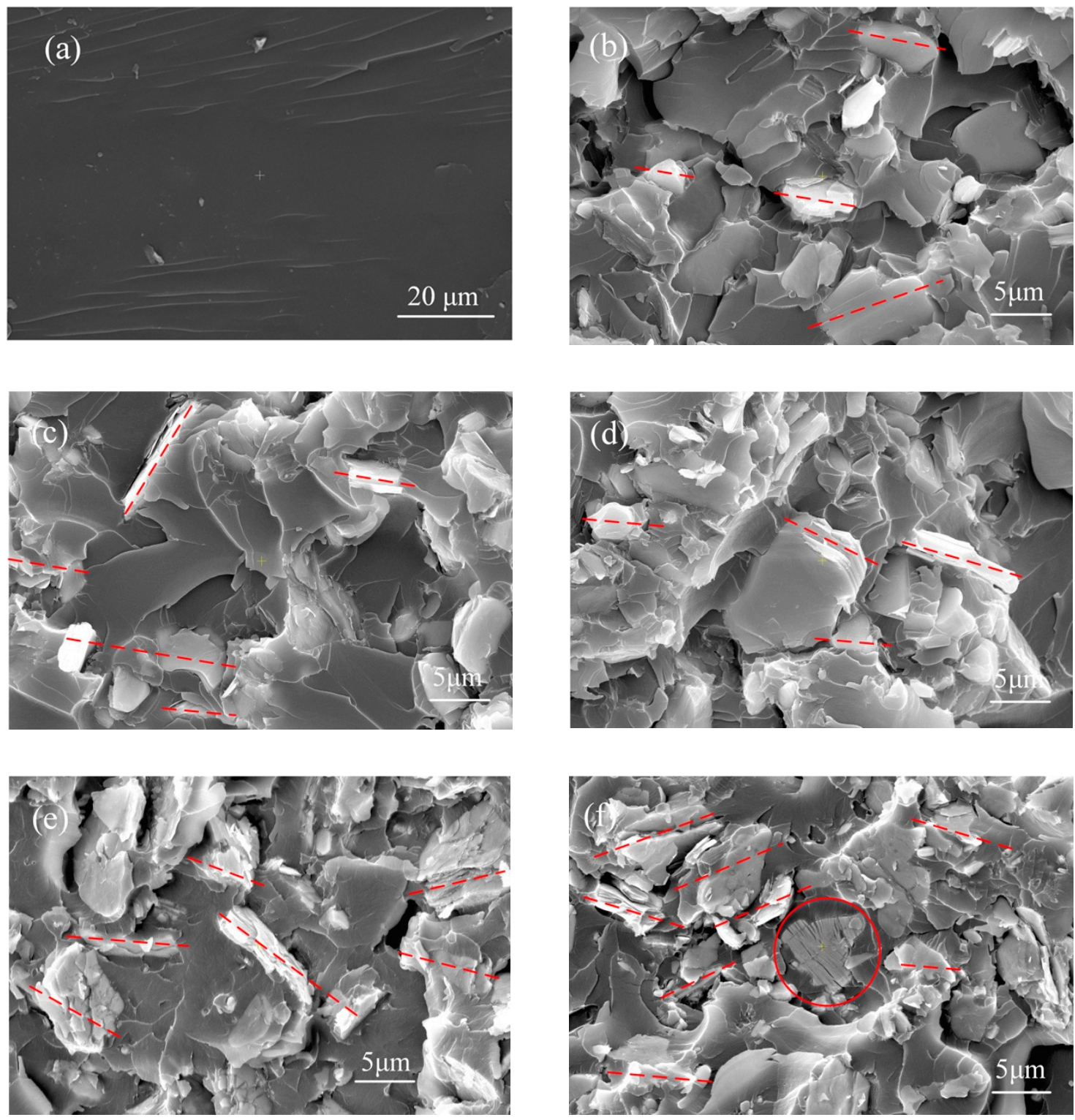

Figure 2. SEM images of cross sections of (a) Pure epoxy, (b-f) HF- $\mathrm{Ti}_{3} \mathrm{C}_{2} \mathrm{~T}_{\mathrm{x}}$ /epoxy composites with filler content of $5 \mathrm{wt} \%, 10 \mathrm{wt} \%, 20 \mathrm{wt} \%, 30 \mathrm{wt} \%$ and $40 \mathrm{wt} \%$, respectively.

Figure 3 shows the measured static water contact angle for above epoxy and epoxy composites, which decreases from $\sim 92^{\circ}$ of pure epoxy to $\sim 72^{\circ}$ of composite with $40 \mathrm{wt} \%$ filler, indicating increased hydrophilicity with higher filler content. This phenomenon can be correlated with the various 
hydrophilic terminals on the HF- $\mathrm{Ti}_{3} \mathrm{C}_{2} \mathrm{~T}_{\mathrm{x}}$ surface, which are also helpful for good compatibility between filler and epoxy matrix, as revealed by the SEM images in Figure 2.

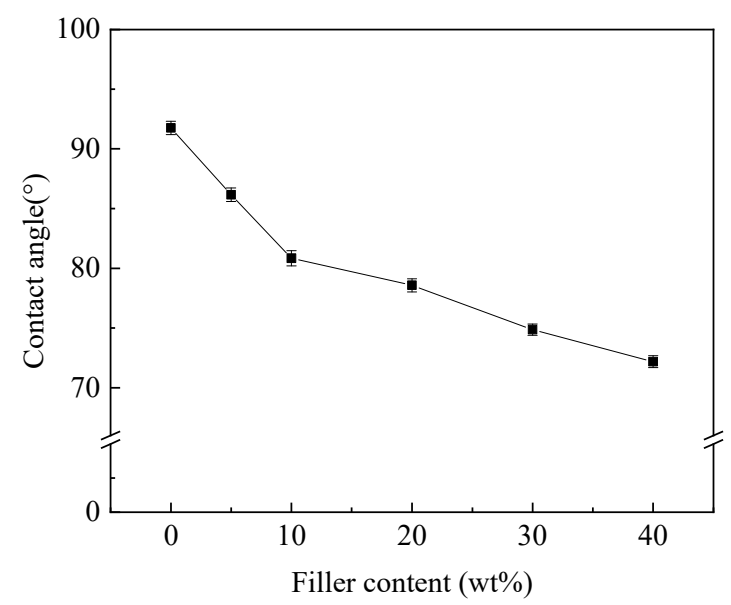

Figure 3. Static water contact angles of the $\mathrm{HF}-\mathrm{Ti}_{3} \mathrm{C}_{2} \mathrm{~T}_{\mathrm{x}} /$ epoxy composites.

Figure 4 shows the density of $\mathrm{HF}-\mathrm{Ti}_{3} \mathrm{C}_{2} \mathrm{~T}_{\mathrm{x}} /$ epoxy composites as a function of filler content, along with the theoretical density calculated by Equation $\mathrm{S} 1$ with epoxy density of $1.22 \mathrm{~g} / \mathrm{cm}^{3}$ and $\mathrm{HF}_{-}-\mathrm{Ti}_{3} \mathrm{C}_{2} \mathrm{~T}_{\mathrm{x}}$ density of $3.00 \mathrm{~g} / \mathrm{cm}^{3}$ (data from 11 Technology). Generally, the experimental results agree well with the theoretical one, i.e., the deviations are within $\pm 3 \%$. Such results suggest that the interfacial compatibility between the filler and the polymer matrix is relatively good and free of voids, which is also confirmed by the SEM results discussed earlier. For the benefit of the broader scientific community, the weight percentage of $\mathrm{HF}-\mathrm{Ti}_{3} \mathrm{C}_{2} \mathrm{~T}_{\mathrm{x}}$ filler in the epoxy composites can be converted into volume percentage by using Equation (1) [30],

$$
V_{f}=\frac{W_{f} / \rho_{f}}{W_{f} / \rho_{f}+\left(1-W_{f}\right) / \rho_{m}}=\frac{\rho_{m} W_{f}}{\rho_{m} W_{f}+\rho_{f}\left(1-W_{f}\right)}
$$

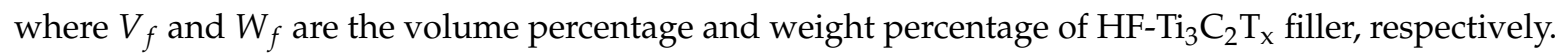
$\rho_{m}$ and $\rho_{f}$ are the densities of epoxy matrix and $\mathrm{HF}-\mathrm{Ti}_{3} \mathrm{C}_{2} \mathrm{~T}_{\mathrm{x}}$ filler, respectively.

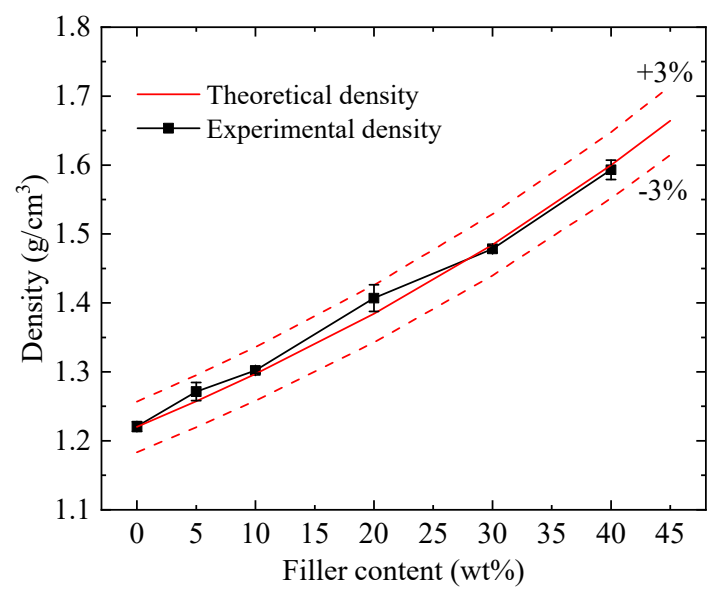

Figure 4. Density of $\mathrm{HF}-\mathrm{Ti}_{3} \mathrm{C}_{2} \mathrm{~T}_{\mathrm{x}} /$ epoxy composites.

The TGA results for pure epoxy and $\mathrm{HF}-\mathrm{Ti}_{3} \mathrm{C}_{2} \mathrm{~T}_{\mathrm{x}}$ /epoxy composites under $\mathrm{Ar}$ are shown in Figure 5, and the residual masses at $800{ }^{\circ} \mathrm{C}$ are listed in Table 1 . Within the temperature range of $50-800{ }^{\circ} \mathrm{C}$, the weight loss behavior of all the samples demonstrates a similar trend. The weight loss of epoxy 
starts at $\sim 350{ }^{\circ} \mathrm{C}$, which becomes insignificant when temperature is higher than $\sim 550{ }^{\circ} \mathrm{C}$, and the residual mass of epoxy at $800{ }^{\circ} \mathrm{C}$ is $8.3 \%$, as listed in Table 1. For epoxy composites, the weight loss starts at lower temperature than that of pure epoxy, and the onset degradation temperature generally decreases as the content of $\mathrm{HF}_{-} \mathrm{Ti}_{3} \mathrm{C}_{2} \mathrm{~T}_{\mathrm{x}}$ filler increases. The fall in thermal stability was confirmed by both DTG curves in Figure $5 \mathrm{~b}$ and the temperature for $5 \%$ of material degrades, as listed in Table 1. Similar thermal behavior of epoxy composites was also observed by Zhang et al. [31]. Such phenomenon can be attributed to the finely dispersed thermally conductive $\mathrm{Ti}_{3} \mathrm{C}_{2} \mathrm{~T}_{\mathrm{x}}$ fillers, which lead to more rapid thermal response of the composites to the temperature rise. However, it is also possible that the introduction of $\mathrm{HF}_{-} \mathrm{Ti}_{3} \mathrm{C}_{2} \mathrm{~T}_{\mathrm{x}}$ may accelerate the degradation of epoxy matrix by some chemical mechanism, which would need further investigations. Table 1 also listed the calculated residual mass of $\mathrm{HF}-\mathrm{Ti}_{3} \mathrm{C}_{2} \mathrm{~T}_{\mathrm{x}}$ /epoxy composites, and the relative deviation between the experimental and calculated values (Supplementary Equation (S2)) is within 1-8\%, indicating the compositions of the as-prepared composites well match the original feed ratios of $\mathrm{HF}-\mathrm{Ti}_{3} \mathrm{C}_{2} \mathrm{~T}_{\mathrm{x}}$ and epoxy components.
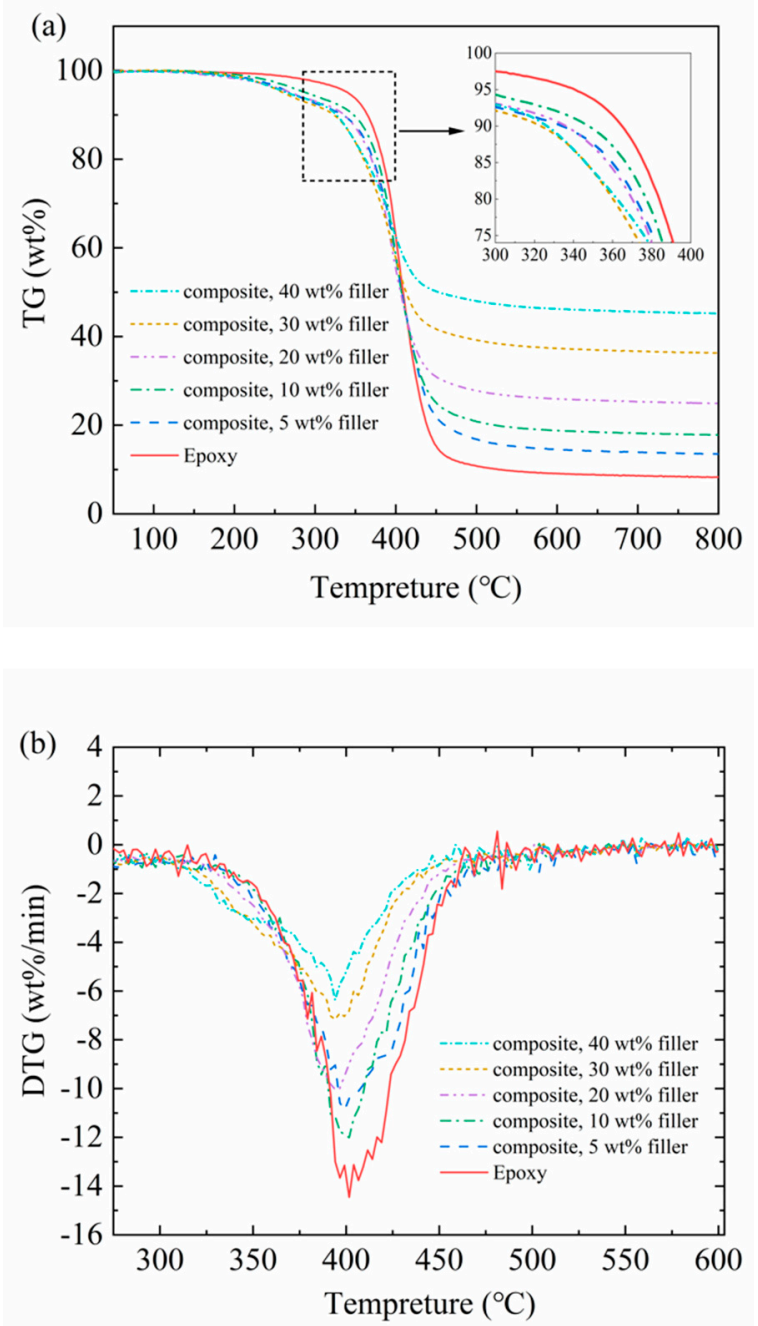

Figure 5. Weight loss curves of epoxy and HF-Ti ${ }_{3} \mathrm{C}_{2} \mathrm{~T}_{\mathrm{x}}$ /epoxy composites under Ar, (a) TG, (b) DTG.

Figure 6 shows the measured thermal conductivity results of the prepared composites, which are highly anisotropic since the in-plane thermal conductivity $\left(k_{/ /}\right)$is much higher than the through-plane one $\left(k_{\perp}\right)$. Both $k_{\perp}$ and $k_{/ /}$increase with the filler content, with $k_{\perp}$ reaching $0.583 \mathrm{Wm}^{-1} \mathrm{~K}^{-1}$ when the filler content increases to $40 \mathrm{wt}^{\mathrm{t}} \mathrm{(}(21.3 \mathrm{vol} \%)$, an enhancement of 2.92 times as compared with epoxy of $0.2 \mathrm{Wm}^{-1} \mathrm{~K}^{-1}$. In comparison, $k_{/ /}$achieves $1.29 \mathrm{Wm}^{-1} \mathrm{~K}^{-1}$ when filler content is only $5 \mathrm{wt} \%(2.1 \mathrm{vol} \%)$, 
and further increases to $2.13 \mathrm{Wm}^{-1} \mathrm{~K}^{-1}$ as filler content increases to $40 \mathrm{wt} \%$, which are 6.45 and 10.65 times of that of epoxy, respectively.

Table 1. Thermogravimetric data of $\mathrm{HF}_{-} \mathrm{Ti}_{3} \mathrm{C}_{2} \mathrm{~T}_{\mathrm{x}}$, epoxy and their composites.

\begin{tabular}{|c|c|c|c|c|}
\hline Samples & $\begin{array}{c}\text { Measured } \\
\text { Residual Mass, } \\
(w t \%)\end{array}$ & $\begin{array}{c}\text { Calculated } \\
\text { Residual Mass } \\
(\mathbf{w t} \%)\end{array}$ & $\begin{array}{c}\text { Relative } \\
\text { Deviation (\%) }\end{array}$ & $\begin{array}{c}\text { Temperature for } \\
5 \mathrm{wt} \% \text { of Material } \\
\text { Degradation }\left({ }^{\circ} \mathrm{C}\right)\end{array}$ \\
\hline HF- $\mathrm{Ti}_{3} \mathrm{C}_{2} \mathrm{~T}_{\mathrm{x}}$ & 92.3 & - & - & - \\
\hline Epoxy & 8.3 & - & - & 364.3 \\
\hline HF- $\mathrm{Ti}_{3} \mathrm{C}_{2} \mathrm{~T}_{\mathrm{x}} /$ epoxy composite, $5 \mathrm{wt} \%$ & 13.5 & 12.5 & 8 & 333.6 \\
\hline HF- $\mathrm{Ti}_{3} \mathrm{C}_{2} \mathrm{~T}_{\mathrm{x}} /$ epoxy composite, $10 \mathrm{wt} \%$ & 17.8 & 16.7 & 7 & 347.5 \\
\hline HF- $\mathrm{Ti}_{3} \mathrm{C}_{2} \mathrm{~T}_{\mathrm{x}} /$ epoxy composite, $20 \mathrm{wt} \%$ & 24.9 & 25.1 & -1 & 335.5 \\
\hline $\mathrm{HF} \mathrm{Ti}_{3} \mathrm{C}_{2} \mathrm{~T}_{\mathrm{x}} /$ epoxy composite, $30 \mathrm{wt} \%$ & 36.3 & 33.5 & 8 & 322.7 \\
\hline HF- $\mathrm{Ti}_{3} \mathrm{C}_{2} \mathrm{~T}_{\mathrm{x}} /$ epoxy composite, $40 \mathrm{wt} \%$ & 45.2 & 41.9 & 8 & 326.6 \\
\hline
\end{tabular}

The enhanced but anisotropic thermal conductivity of epoxy composites can be reasonably related to the $2 \mathrm{D}$ structure of $\mathrm{HF}-\mathrm{Ti}_{3} \mathrm{C}_{2} \mathrm{~T}_{\mathrm{x}}$ fillers and their distribution in the epoxy matrix. It is already known that 2D fillers, such as graphene [24,32] and boron nitride(BN) [33,34], can more effectively enhance composite thermal conductivity along the lateral direction of the platelet-shaped fillers, and this enhancement is more pronounced when the fillers tend to align in the composites, resulting in highly anisotropic thermal conductivity of the composite. In this work, the $\mathrm{HF}_{-} \mathrm{Ti}_{3} \mathrm{C}_{2} \mathrm{~T}_{\mathrm{x}} / \mathrm{epoxy}$ composites were prepared by cast molding. The composite fluid containing $2 \mathrm{D}$ fillers was continuously stirred at high speed for more than $2 \mathrm{~h}$ and then slowly poured into shallow mold where it gradually cured, and the resulting filler distribution is generally aligned. Su et al. [35] applied very similar procedures to prepare 2D graphite/epoxy composites, and they also obtained aligned filler distribution in the in-plain direction. Therefore, the aligned filler distribution might be attributed to the shear and centrifugal force in stirring. In addition, the gravity and viscosity force might also influence filler distribution. As a result of the aligned filler distribution, the in-plane thermal conductivity is effectively improved even with very small amount of filler, such as the 6.45 times enhancement of in-plane thermal conductivity achieved by $5 \mathrm{wt} \% \mathrm{HF}-\mathrm{Ti}_{3} \mathrm{C}_{2} \mathrm{~T}_{\mathrm{x}}$ fillers. When the filler content increases, the distance between fillers reduces and the connection between fillers increases, as observed by SEM images in Figure 2. Consequently, heat conducting chain/network gradually forms as filler content increases, which contributes to the improved composite thermal conductivity. However, percolation phenomenon (i.e., sharp increase in thermal conductivity) is not observed in Figure 6, even when the filler content increased to $40 \mathrm{wt} \%$. This may be related to the relative limited aspect ratio (around 3 6) of the prepared micro-sized $\mathrm{HF}-\mathrm{Ti}_{3} \mathrm{C}_{2} \mathrm{~T}_{\mathrm{x}}$ platelets, as compared with its derivants of ML- $\mathrm{Ti}_{3} \mathrm{C}_{2} \mathrm{~T}_{\mathrm{x}}$ nanoflake and $F L-T_{3} C_{2} T_{x}$ nanosheets. In other words, if nano-sized ML-Ti ${ }_{3} C_{2} T_{x}$ or $F L-T_{3} C_{2} T_{x}$ were used, a higher thermal conductivity might be expected, which will be studied in future work.

Figure 6 also shows the calculated thermal conductivity results obtained by a specialized model which was formerly developed for 2D BN/polymer composites [36,37] and was recently applied to analyze the $\mathrm{Ti}_{3} \mathrm{C}_{2} \mathrm{~T}_{x}$ /epoxy composites. Briefly, this model takes into account the key parameters including filler orientation angle and filler aspect ratio (i.e., determined by lateral size and thickness), and simultaneously calculates $k_{\perp}$ and $k_{/ /}$for a given filler content. In this work, the filler orientation angle and aspect ratio are estimated from SEM images (Supplementary Materials Section S3) to be ca. $20^{\circ}$ and 3.5, respectively. By using these parameters, together with an estimated thermal conductivity of $100 \mathrm{Wm}^{-1} \mathrm{~K}^{-1}$ for $\mathrm{Ti}_{3} \mathrm{C}_{2} \mathrm{~T}_{\mathrm{x}}$ filler [28], the modeling results fit quite well with the experimental results in both through-plane and in-plane directions, as shown in Figure 6, confirming the highly anisotropic thermal conductivity results from the platelet shape of the $2 \mathrm{D} \mathrm{Ti}_{3} \mathrm{C}_{2} \mathrm{~T}_{\mathrm{x}}$ filler and their close-to-horizontal distribution. 


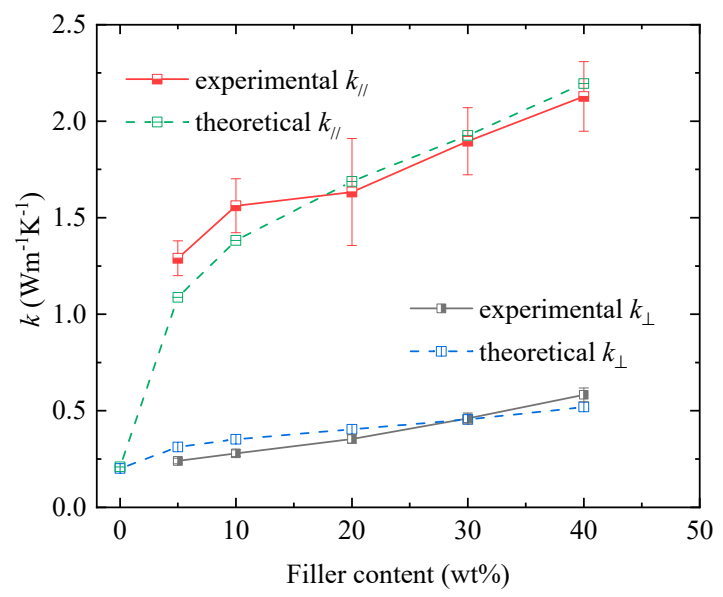

Figure 6. In-plane and through-plane thermal conductivities of $\mathrm{HF}-\mathrm{Ti}_{3} \mathrm{C}_{2} \mathrm{~T}_{\mathrm{x}} /$ epoxy composites, in which the theoretical ones are simultaneously calculated by Chen model $[36,37]$.

Figure 7 shows the dielectric properties of the prepared HF- $\mathrm{Ti}_{3} \mathrm{C}_{2} \mathrm{~T}_{\mathrm{x}} / \mathrm{epoxy}$ composites which were measured at room temperature within the frequency range of $10^{2}$ to $5 \times 10^{6} \mathrm{~Hz}$. As shown in Figure $7 \mathrm{a}$, the dielectric permittivity $\varepsilon$ of each sample decreases slightly as the frequency increases. Similar phenomenon were also observed for epoxy composites [11,38,39], which can be attributed to the relaxation process [11,38], i.e., the decrease in dipolar polarization and interfacial polarization [39]. Moreover, the fact that the decrease of the dielectric permittivity with the frequency is quite smooth (i.e., dielectric permittivity decreases slightly with the increasing frequency) may reflect a uniform filler distribution in the epoxy matrix [11]. Figure 7a also shows that the dielectric permittivity of epoxy composite increases as the filler content increases. Take the data at $10^{3} \mathrm{~Hz}$ for example, as shown in Figure 7c, the dielectric permittivity increases to $6.3 \mathrm{when}$ the filler content is $40 \mathrm{wt} \%$, which is 2.25 times of pure epoxy $(\varepsilon=2.8)$. For other frequency, there is similar enhancement ratio since the variation curves are nearly parallel to each other. It is known that the dielectric permittivity of polymer composites can be improved by adding conductive fillers [4,39], which can lead to drastic increase in the vicinity of percolation threshold [4]. Therefore, the enhanced dielectric permittivity of epoxy composite in this work is induced by the conductive HF- $\mathrm{Ti}_{3} \mathrm{C}_{2} \mathrm{~T}_{\mathrm{x}}$ fillers. However, the achieved enhancement is

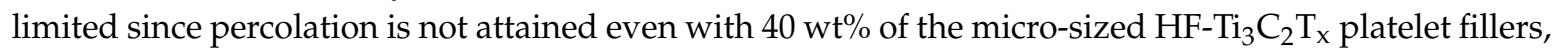
which is consistent with the above analysis for thermal conductivity enhancement. From Figure $7 \mathrm{~b}$, the dielectric loss (i.e., loss tangent) generally increases with the increasing frequency and filler content, which is mainly due to relaxation process in polymer. The highest dielectric loss of about 0.02 appears at high frequency on the order of $10^{6}$. At $10^{3} \mathrm{~Hz}$, the dielectric losses of all composites are within 0.01, as shown in Figure 7c. 
(a)

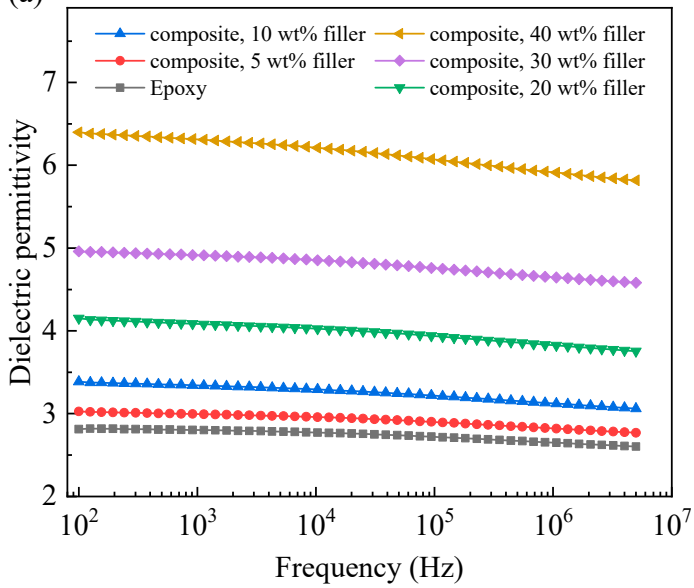

(b)

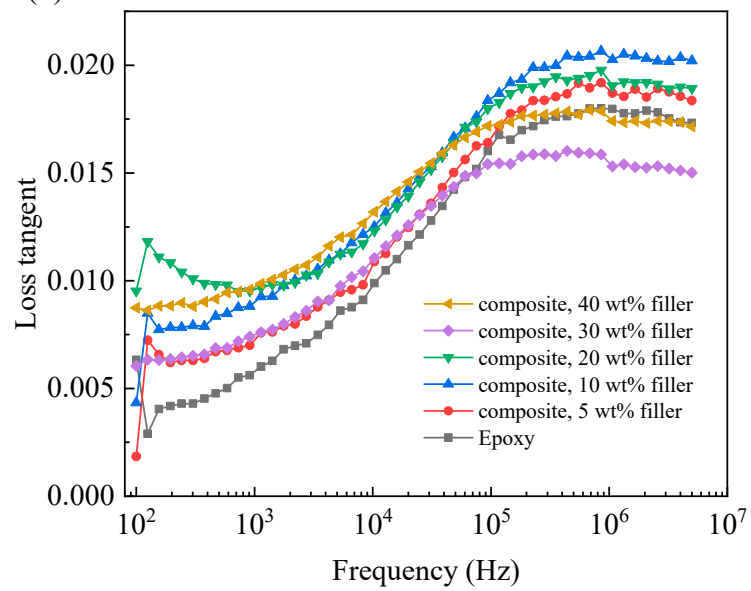

(c)

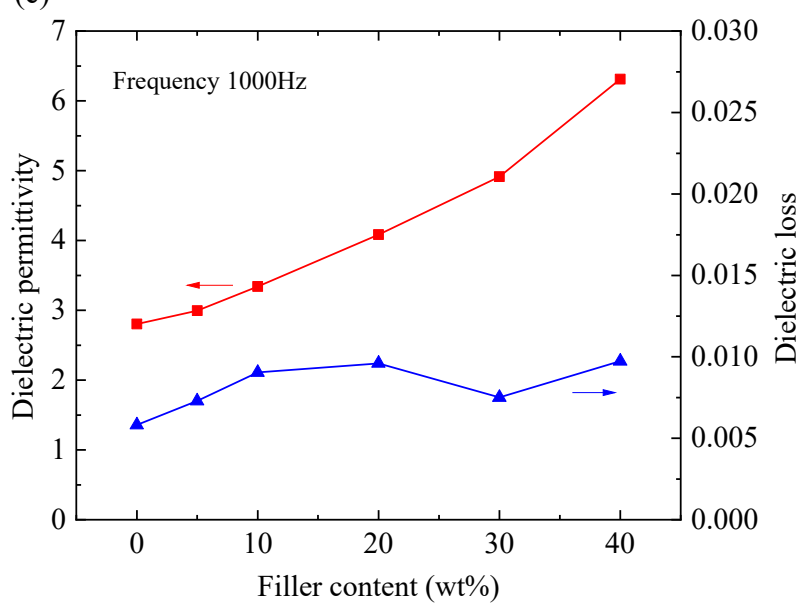

Figure 7. Frequency dependence of (a) dielectric permittivity and (b) dielectric loss of $\mathrm{HF}-\mathrm{Ti}_{3} \mathrm{C}_{2} \mathrm{~T}_{\mathrm{x}} / \mathrm{epoxy}$ composites, and (c) variation of dielectric properties with the filler content at $10^{3} \mathrm{~Hz}$.

\section{Conclusions}

In this work, epoxy composites were fabricated by using $H F-\mathrm{Ti}_{3} \mathrm{C}_{2} \mathrm{~T}_{\mathrm{x}}$ micro-platelet fillers, which can be efficiently and massively produced by direct $\mathrm{HF}$ etching of $\mathrm{Ti}_{3} \mathrm{AlC}_{2}$ powders. 
Both thermal and dielectric performance were improved by the addition of $\mathrm{HF}-\mathrm{Ti}_{3} \mathrm{C}_{2} \mathrm{~T}_{\mathrm{x}}$ fillers. On the one hand, $\mathrm{HF}_{-} \mathrm{Ti}_{3} \mathrm{C}_{2} \mathrm{~T}_{\mathrm{x}}$ fillers effectively enhanced the thermal conductivity of epoxy composites. The through-plane thermal conductivity $k_{\perp}$ achieved $0.583 \mathrm{Wm}^{-1} \mathrm{~K}^{-1}$ when the filler content was $40 \mathrm{wt} \%(21.3 \mathrm{vol} \%)$, an enhancement of 2.92 times as compared with pure epoxy. As for in-plane thermal conductivity $\mathrm{k}_{/ /}$, it reached $1.29 \mathrm{Wm}^{-1} \mathrm{~K}^{-1}$ when the filler content was only $5 \mathrm{wt} \%(2.1 \mathrm{vol} \%)$, and it further increased to $2.13 \mathrm{Wm}^{-1} \mathrm{~K}^{-1}$ when the filler content was $40 \mathrm{wt} \%$, achieving the enhancements of 6.45 and 10.65 times, respectively. The enhanced but anisotropic thermal conductivity was attributed to the 2D structure of $\mathrm{HF}_{-} \mathrm{Ti}_{3} \mathrm{C}_{2} \mathrm{~T}_{\mathrm{x}}$ fillers and their distribution in the epoxy matrix, as observed by SEM observations. On the other hand, the conductive HF-Ti ${ }_{3} \mathrm{C}_{2} \mathrm{~T}_{\mathrm{x}}$ fillers also contributed to the dielectric permittivity of epoxy composite, and an enhancement factor of 2.25 was achieved by $40 \mathrm{wt} \%$ fillers. Meanwhile, the dielectric loss was also slightly increased, but all the measured results were within a limited value of 0.02 . Therefore, our work has provided a promising way to make use of these HF- $\mathrm{Ti}_{3} \mathrm{C}_{2} \mathrm{~T}_{\mathrm{x}}$ micro-platelets as effective fillers to improve both the thermal and dielectric performances of epoxy composites.

Supplementary Materials: The following are available online at http://www.mdpi.com/2073-4360/12/7/1608/s1.

Author Contributions: Conceptualization, L.C. and J.L.; methodology, J.L.; software, K.C.; validation, Y.C., X.G., and P.S.; formal analysis, L.C.; investigation, Y.C.; resources, P.S. and D.L.; data curation, Y.C.; writing-original draft preparation, L.C.; writing-review and editing, J.L.; visualization, L.C.; supervision, L.C. and J.L.; project administration, L.C.; funding acquisition, L.C. and J.L. All authors have read and agreed to the published version of the manuscript.

Funding: This research was funded by National Natural Science Foundation of China (51776069, 51773058), the Beijing Key Research and Development Program (No. Z181100005118013) and the Fundamental Research Funds for the Central Universities (Grant No. 2019MS039).

Conflicts of Interest: The authors declare no conflict of interest.

\section{References}

1. Han, Z.; Fina, A. Thermal conductivity of carbon nanotubes and their polymer nanocomposites: A review. Prog. Polym. Sci. 2011, 36, 914-944. [CrossRef]

2. Burger, N.; Laachachi, A.; Ferriol, M.; Lutz, M.; Toniazzo, V.; Ruch, D. Review of thermal conductivity in composites: Mechanisms, parameters and theory. Prog. Polym. Sci. 2016, 61, 1-28. [CrossRef]

3. Chen, H.; Ginzburg, V.V.; Yang, J.; Yang, Y.; Liu, W.; Huang, Y.; Du, L.; Chen, B. Thermal conductivity of polymer-based composites: Fundamentals and applications. Prog. Polym. Sci. 2016, 59, 41-85. [CrossRef]

4. Dang, Z.-M.; Yuan, J.-K.; Zha, J.-W.; Zhou, T.; Li, S.-T.; Hu, G.-H. Fundamentals, processes and applications of high-permittivity polymer-matrix composites. Prog. Mater. Sci. 2012, 57, 660-723. [CrossRef]

5. Shahil, K.M.; Balandin, A.A. Graphene-multilayer graphene nanocomposites as highly efficient thermal interface materials. Nano Lett. 2012, 12, 861-867. [CrossRef] [PubMed]

6. Cao, B.-Y.; Kong, J.; Xu, Y.; Yung, K.-L.; Cai, A. Polymer Nanowire Arrays with High Thermal Conductivity and Superhydrophobicity Fabricated by a Nano-Molding Technique. Heat Transf. Eng. 2013, 34, 131-139. [CrossRef]

7. Chen, K.; Chen, Y.; She, Y.; Song, M.; Wang, S.; Chen, L. Construction of effective symmetrical air-cooled system for battery thermal management. Appl. Therm. Eng. 2020, 166, 114679. [CrossRef]

8. Chen, L.; Li, Z.; Guo, Z.-Y. Experimental investigation of plastic finned-tube heat exchangers, with emphasis on material thermal conductivity. Exp. Therm. Fluid Sci. 2009, 33, 922-928. [CrossRef]

9. T'Joen, C.; Park, Y.; Wang, Q.; Sommers, A.; Han, X.; Jacobi, A. A review on polymer heat exchangers for HVAC\&R applications. Int. J. Refrig. 2009, 32, 763-779.

10. Arbatti, M.; Shan, X.; Cheng, Z.-Y. Ceramic-Polymer Composites with High Dielectric Constant. Adv. Mater. 2007, 19, 1369-1372. [CrossRef]

11. Su, Y.; Ba, C.; Wang, F. Improved dielectric permittivity of NBCTO/epoxy composite films with low dielectric loss. SN Appl. Sci. 2019, 1, 1147. [CrossRef] 
12. Ran, F.; Xu, X.; Pan, D.; Liu, Y.; Bai, Y.; Shao, L. Ultrathin 2D Metal-Organic Framework Nanosheets In Situ Interpenetrated by Functional CNTs for Hybrid Energy Storage Device. Nano Micro Lett. 2020, 12, 46. [CrossRef]

13. Naguib, M.; Kurtoglu, M.; Presser, V.; Lu, J.; Niu, J.; Heon, M.; Hultman, L.; Gogotsi, Y.; Barsoum, M.W. Two-dimensional nanocrystals produced by exfoliation of $\mathrm{Ti}_{3} \mathrm{AlC}_{2}$. Adv. Mater. 2011, 23, 4248-4253. [CrossRef] [PubMed]

14. Naguib, M.; Mochalin, V.N.; Barsoum, M.W.; Gogotsi, Y. 25th anniversary article: MXenes: A new family of two-dimensional materials. Adv. Mater. 2014, 26, 992-1005. [CrossRef] [PubMed]

15. Alhabeb, M.; Maleski, K.; Anasori, B.; Lelyukh, P.; Clark, L.; Sin, S.; Gogotsi, Y. Guidelines for Synthesis and Processing of Two-Dimensional Titanium Carbide (Ti3C2Tx MXene). Chem. Mater. 2017, 29, 7633-7644. [CrossRef]

16. Miranda, A.; Halim, J.; Lorke, A.; Barsoum, M.W. Rendering Ti3C2Tx (MXene) monolayers visible. Mater. Res. Lett. 2017, 5, 322-328. [CrossRef]

17. Lukatskaya, M.R.; Mashtalir, O.; Ren, C.E.; Dall'Agnese, Y.; Rozier, P.; Taberna, P.L.; Naguib, M.; Simon, P.; Barsoum, M.W.; Gogotsi, Y. Cation intercalation and high volumetric capacitance of two-dimensional titanium carbide. Science 2013, 341, 1502-1505. [CrossRef]

18. Ghidiu, M.; Lukatskaya, M.R.; Zhao, M.Q.; Gogotsi, Y.; Barsoum, M.W. Conductive two-dimensional titanium carbide 'clay' with high volumetric capacitance. Nature 2014, 516, 78-81. [CrossRef]

19. Shahzad, F.; Alhabeb, M.; Hatter, C.B.; Anasori, B.; Man Hong, S.; Koo, C.M.; Gogotsi, Y. Electromagnetic interference shielding with 2D transition metal carbides (MXenes). Science 2016, 353, 1137-1140. [CrossRef]

20. Deng, B.; Xiang, Z.; Xiong, J.; Liu, Z.; Yu, L.; Lu, W. Sandwich-Like Fe\&TiO2@C Nanocomposites Derived from MXene/Fe-MOFs Hybrids for Electromagnetic Absorption. Nano Micro Lett. 2020, 12, 55.

21. Zhang, Q.; Teng, J.; Zou, G.; Peng, Q.; Du, Q.; Jiao, T.; Xiang, J. Efficient phosphate sequestration for water purification by unique sandwich-like MXene/magnetic iron oxide nanocomposites. Nanoscale 2016, 8, 7085-7093. [CrossRef] [PubMed]

22. Rasool, K.; Helal, M.; Ali, A.; Ren, C.E.; Gogotsi, Y.; Mahmoud, K.A. Antibacterial Activity of Ti3C2Tx MXene. ACS Nano 2016, 10, 3674-3684. [CrossRef] [PubMed]

23. Ling, Z.; Ren, C.E.; Zhao, M.Q.; Yang, J.; Giammarco, J.M.; Qiu, J.S.; Barsoum, M.W.; Gogotsi, Y. Flexible and conductive MXene films and nanocomposites with high capacitance. Proc. Natl. Acad. Sci. USA 2014, 111, 16676-16681. [CrossRef] [PubMed]

24. Shen, X.; Wang, Z.Y.; Wu, Y.; Liu, X.; He, Y.B.; Kim, J.K. Multilayer Graphene Enables Higher Efficiency in Improving Thermal Conductivities of Graphene/Epoxy Composites. Nano Lett. 2016, 16, 3585-3593. [CrossRef]

25. Sun, Y.; Chen, L.; Lin, J.; Cui, P.; Li, M.; Du, X. Thermal conductivity of epoxy composites filled by thermally reduced graphite oxide with different reduction degree. J. Compos. Mater. 2017, 51, 1743-1752. [CrossRef]

26. Sun, Y.; Chen, L.; Cui, L.; Zhang, Y.; Du, X. Molecular dynamics simulation of cross-linked epoxy resin and its interaction energy with graphene under two typical force fields. Comput. Mater. Sci. 2018, 143, 240-247. [CrossRef]

27. Khan, M.; Khurram, A.A.; Li, T.H.; Zhao, T.K.; Subhani, T.; Gul, I.H.; Ali, Z.; Patel, V. Synergistic effect of organic and inorganic nano fillers on the dielectric and mechanical properties of epoxy composites. J. Mater. Sci. Technol. 2018, 34, 2424-2430. [CrossRef]

28. Chen, L.; Shi, X.G.; Yu, N.J.; Zhang, X.; Du, X.Z.; Lin, J. Measurement and Analysis of Thermal Conductivity of Ti3C2Tx MXene Films. Materials 2018, 11, 1701. [CrossRef]

29. Chang, F.; Li, C.; Yang, J.; Tang, H.; Xue, M. Synthesis of a new graphene-like transition metal carbide by de-intercalating Ti3AlC2. Mater. Lett. 2013, 109, 295-298. [CrossRef]

30. Aakyiir, M.; Araby, S.; Michelmore, A.; Meng, Q.; Amer, Y.; Yao, Y.; Li, M.; Wu, X.; Zhang, L.; Ma, J. Elastomer nanocomposites containing MXene for mechanical robustness and electrical and thermal conductivity. Nanotechnology 2020, 31, 315715. [CrossRef]

31. Zhang, H.; Wang, L.; Zhou, A.; Shen, C.; Dai, Y.; Liu, F.; Chen, J.; Li, P.; Hu, Q. Effects of 2-D transition metal carbide Ti2CTx on properties of epoxy composites. RSC Adv. 2016, 6, 87341-87352. [CrossRef]

32. Yu, W.; Xie, H.; Chen, L.; Zhu, Z.; Zhao, J.; Zhang, Z. Graphene based silicone thermal greases. Phys. Lett. A 2014, 378, 207-211. [CrossRef] 
33. Tanimoto, M.; Yamagata, T.; Miyata, K.; Ando, S. Anisotropic thermal diffusivity of hexagonal boron nitride-filled polyimide films: Effects of filler particle size, aggregation, orientation, and polymer chain rigidity. ACS Appl. Mater. Interfaces 2013, 5, 4374-4382. [CrossRef] [PubMed]

34. Xie, B.-H.; Huang, X.; Zhang, G.-J. High thermal conductive polyvinyl alcohol composites with hexagonal boron nitride microplatelets as fillers. Compos. Sci. Technol. 2013, 85, 98-103. [CrossRef]

35. Su, Z.; Wang, H.; Tian, K.; Huang, W.; Guo, Y.; He, J.; Tian, X. Multifunctional anisotropic flexible cycloaliphatic epoxy resin nanocomposites reinforced by aligned graphite flake with non-covalent biomimetic functionalization. Compos. Part A Appl. Sci. Manuf. 2018, 109, 472-480. [CrossRef]

36. Chen, L.; Sun, Y.-Y.; Xu, H.-F.; He, S.-J.; Wei, G.-S.; Du, X.-Z.; Lin, J. Analytic modeling for the anisotropic thermal conductivity of polymer composites containing aligned hexagonal boron nitride. Compos. Sci. Technol. 2016, 122, 42-49. [CrossRef]

37. Chen, L.; Xu, H.F.; Sun, Y.Y.; Du, X.Z.; He, S.J.; Lin, J.; Nazarenko, S. Modeling of anisotropic thermal conductivity of polymer composites containing aligned boron nitride platelets: Effect of processing methods. Polym. Compos. 2017, 38, 2670-2678. [CrossRef]

38. Ramajo, L.; Reboredo, M.M.; Castro, M.S. BaTiO3-Epoxy Composites for Electronic Applications. Int. J. Appl. Ceram. Technol. 2010, 7, 444-451.

39. Tsangaris, G.M.; Psarras, G.C. The dielectric response of a polymeric three-component composite. J. Mater. Sci. 1999, 34, 2151-2157. [CrossRef]

(C) 2020 by the authors. Licensee MDPI, Basel, Switzerland. This article is an open access article distributed under the terms and conditions of the Creative Commons Attribution (CC BY) license (http://creativecommons.org/licenses/by/4.0/). 